\title{
Imaging Oxygen Metabolism in Acute Stroke Using MRI
}

\author{
Hongyu An • Andria L. Ford $\cdot$ Katie D. Vo • \\ Qingwei Liu $\cdot$ Yasheng Chen $\cdot$ Jin-Moo Lee • \\ Weili Lin
}

Published online: 21 January 2014

(C) Springer Science+Business Media New York 2014

\begin{abstract}
The ability to image the ischemic penumbra during hyperacute stroke promises to identify patients who may benefit from treatment intervention beyond population-defined therapeutic time windows. MR blood oxygenation leveldependent (BOLD) contrast imaging has been explored in ischemic stroke. This review provides an overview of several BOLD-based methods, including susceptibility-weighted imaging, R2, R2*, R2', R2* under oxygen challenge, MR_OEF and MROMI approaches to assess cerebral oxygen metabolism in ischemic stroke. We will review the underlying pathophysiological basis of the imaging approaches, followed by a brief introduction of BOLD contrast. Finally, we will discuss the applications of the BOLD approaches in patients with ischemic stroke. BOLD-based methods hold promise for imaging tissue oxygenation during acute ischemia. Further technical refinement and validation studies in stroke patients against positron emission tomography measurements are needed.
\end{abstract}

Keywords MRI - BOLD - Oxygen extraction fraction · Cerebral blood flow Oxygen metabolism - Ischemia

This article is part of the Topical Collection on Advances Neuro-Imaging.

H. An $(\bowtie) \cdot$ Q. Liu · Y. Chen · W. Lin

Department of Radiology and Biomedical Research Imaging

Center, University of North Carolina at Chapel Hill, CB\#7513, Chapel Hill, NC 27599, USA

e-mail: hongyuan@med.unc.edu

A. L. Ford · J.-M. Lee

Department of Neurology, Washington University School of Medicine, St. Louis, MO, USA

K. D. Vo · J.-M. Lee

Department of Radiology, Washington University School of Medicine, St. Louis, MO, USA

\section{Introduction}

Cerebral oxygen metabolism is essential for generating a steady supply of energy for the normal neuronal activity of the brain. Occlusion of a cerebral artery leads to reduction of oxygen and substrate supply to brain tissue resulting in ischemia and eventual infarction. Emergent evaluation and treatment are required to forestall rapidly evolving ischemic injury [1]. Depending on the depth of ischemia, time to treatment and response to treatment, ischemic tissue can be classified into core, penumbra and oligemia. Severe ischemia in the core rapidly leads to irreversible injury regardless of treatment. The ischemic penumbra maintains sufficient flow to preserve tissue structure but impair neural function [2], but rapidly evolves to infarction if therapeutic intervention is not instituted in a timely manner [3]. Oligemic tissue demonstrates decreased flow, but not sufficient to result in tissue injury even in the absence of treatment. A pooled analysis of several clinical trials has demonstrated that benefits of treatment decrease, while risks increase, as a function of time [1].

Thus far, intravenous (IV) tissue plasminogen activator (tPA) remains the only FDA-approved medication for treating acute ischemic stroke patients. Improved outcomes have been demonstrated in patients treated within $3 \mathrm{~h}$ [4] and more recently within $4.5 \mathrm{~h}$ of symptom onset [5] based on population studies. Several additional trials have failed to demonstrate the efficacy of IV tPA beyond $4.5 \mathrm{~h}$ [6-8]. In light of these clinical trials, the current recommended therapeutic time window of IV tPA for ischemic stroke is $4.5 \mathrm{~h}$. This short time window has greatly limited IV tPA treatment to only $3.4-5.2 \%$ of stroke patients $[9,10]$. It has been suggested that endovascular approaches, including thrombectomy, may enhance chances for recanalization. However, a recent randomized controlled trial did not 
show a treatment benefit in patients who had endovascular embolectomy using MR imaging criteria for treatment [11]. The use of an early generation clot retrieval device might, in part, be responsible for the negative trial results. More recently, the new SOLITAIRE ${ }^{\mathrm{TM}}$ Flow Restoration device achieved substantially better vessel recanalization, safety and clinical outcomes compared to earlier generation retrieval devices [12].

It is likely that the therapeutic window for tPA, endovascular thrombectomy or other potential therapies may vary between individuals [13], depending on a host of factors such as vascular anatomy, collateral flow patterns, comorbidities and body temperature [13]. Imaging the ischemic penumbra during hyperacute stroke may be one approach to individualize therapeutic opportunities beyond population-defined time windows.

Over the past 2 decades, the magnetic resonance (MR) diffusion-perfusion (DWI/PWI) mismatch (DPM) has been widely used as a surrogate imaging biomarker for the ischemic penumbra [14-16]. However, it has been demonstrated that the diffusion lesion (the assumed core) may reverse after reperfusion and that DPM overestimates the size of the penumbra [17-24].

On the other hand, imaging tissue oxygen metabolism may provide a more direct assessment of tissue viability [25-28] when compared to that offered by DPM. Positron emission tomography (PET) ${ }^{15} \mathrm{O}$ imaging measures the quantitative cerebral blood flow (CBF), oxygen extraction fraction $(\mathrm{OEF})$ and cerebral metabolic rate of oxygen utilization $\left(\mathrm{CMRO}_{2}=\mathrm{CBF} \times \mathrm{CaO}_{2} \times \mathrm{OEF}\right.$, where $\mathrm{CaO}_{2}$ is the arterial oxygen content). $\mathrm{CBF} \times \mathrm{CaO}_{2}$ and $\mathrm{OEF}$ reflect the oxygen delivery and demand, respectively, whereas $\mathrm{CMRO}_{2}$ reveals the balance between these two. It has been suggested that $\mathrm{CMRO}_{2}$ is a more specific marker for tissue viability $[25,26]$. However, while PET ${ }^{15} \mathrm{O}$ imaging is a validated method for measuring regional oxygen metabolism, the 2-min half-life time of ${ }^{15} \mathrm{O}$ and the need for arterial blood sampling has greatly hindered its utilization in the setting of acute stroke. In light of the practical challenge of PET ${ }^{15} \mathrm{O}$ imaging, non-invasive MR blood oxygen level-dependent (BOLD)-based approaches have been explored. In this review, we will introduce the underlying pathophysiological basis of identifying the 'atrisk' tissue using oxygen metabolic imaging in acute stroke, followed by MR BOLD contrast. We will review several MR BOLD contrast-based approaches for penumbral imaging in acute stroke.

Hemodynamic and Metabolic Changes During Acute Ischemia

When an artery becomes narrowed or occluded, the mean arterial pressure (MAP) in the distal circulation may fall, depending on the degree of stenosis and the adequacy of collateral blood flow [29]. This decrease in MAP leads to a reduction in cerebral perfusion pressure (CPP) [30, 31]. In order to compensate for decreasing CPP, brain arterioles dilate to reduce vascular resistance in attempts to maintain constant CBF (autoregulation) [32, 33]. As CPP continues to decrease and $\mathrm{CBF}$ is maximally increased, a second compensatory mechanism results in an increase in the fraction of total oxygen extracted from blood (OEF) [25, 34] to maintain a close to normal oxygen metabolism. This phenomenon, termed "misery perfusion" [35], represents ischemic tissue with an elevated $\mathrm{OEF}$ and reduced $\mathrm{CBF}$ that is "at risk" for future infarction if left treated [35]. Misery perfusion, regarded as a signature of the ischemic penumbra [36-38], has been identified in some stroke patients up to days after symptom onset [39]: evidence of misery perfusion was found in $100,83,57$ and $35-45 \%$ of patients within 9, 12, $24 \mathrm{~h}$ and 3-4 days after stroke onset [40]. Collectively, these studies support the notion that penumbra may exist in some patients well beyond currently defined therapeutic time windows, but the proportion of patients with viable penumbra diminishes over time at different rates. Therefore, a penumbral imaging biomarker based on oxygen metabolism holds promise for identifying patients who may be eligible for an extended therapeutic time window with a goal of maximizing the treatment benefit and minimizing the associated risk.

\section{Blood Oxygen Level-Dependent Contrast (BOLD)}

Blood is composed of plasma, red blood cells (RBCs), various leukocytes (white blood cells) and platelets. Circulating RBCs contain hemoglobin, which is found in both the oxy- $(\mathrm{Hb})$ and deoxyhemoglobin $(\mathrm{dHb})$ states, depending on the binding of oxygen to the heme moiety within the hemoglobin protein complex. Iron in the heme moiety of deoxyhemoglobin is in a high spin ferrous $\mathrm{Fe}^{2+}$ state with four of its six outer electrons being unpaired. The unpaired electron spins induce large magnetic moments that make deoxyhemoglobin an endogenous paramagnetic contrast agent [41]. In contrast, iron in oxygenated hemoglobin has an electron that is partially transferred to the oxygen molecule, resulting in a low-spin state heme iron. Hence, oxyhemoglobin exhibits diamagnetic properties.

The susceptibility difference between deoxyhemoglobin and oxyhemoglobin provides a powerful endogenous MR contrast that is dependent on the blood oxygenation level. Relaxation rates $\mathrm{R} 2$ (1/T2), R2*(1/T2*) and $\mathrm{R} 2{ }^{\prime}(=\mathrm{R} 2 *-\mathrm{R} 2)$ are increased with increasing deoxyhemoglobin concentration [42-45]. Several MR BOLD methods directly or indirectly measure OEF or oxygen metabolism in an effort to image viable but at-risk tissue. 
Fig. 1 DWI, PWI and SWI imaging in a stroke patient scanned at 5, $48 \mathrm{~h}$ and 12 weeks after stroke onset. A 53 year-old male who presented with aphasia and mild right hemiparesis (NIHSS $=10$ ) was imaged at $5,48 \mathrm{~h}$ and 12 weeks after symptom onset. Prominent veins (marked by arrows) were clearly visible immediately adjacent to the ischemic lesion at $5 \mathrm{~h}$, while the contrast between the veins and surrounding tissues diminished at $48 \mathrm{~h}$. Finally, the veins around the final infarction appeared to be very similar to that of the contralateral hemisphere (from An et al. [47], with permission)

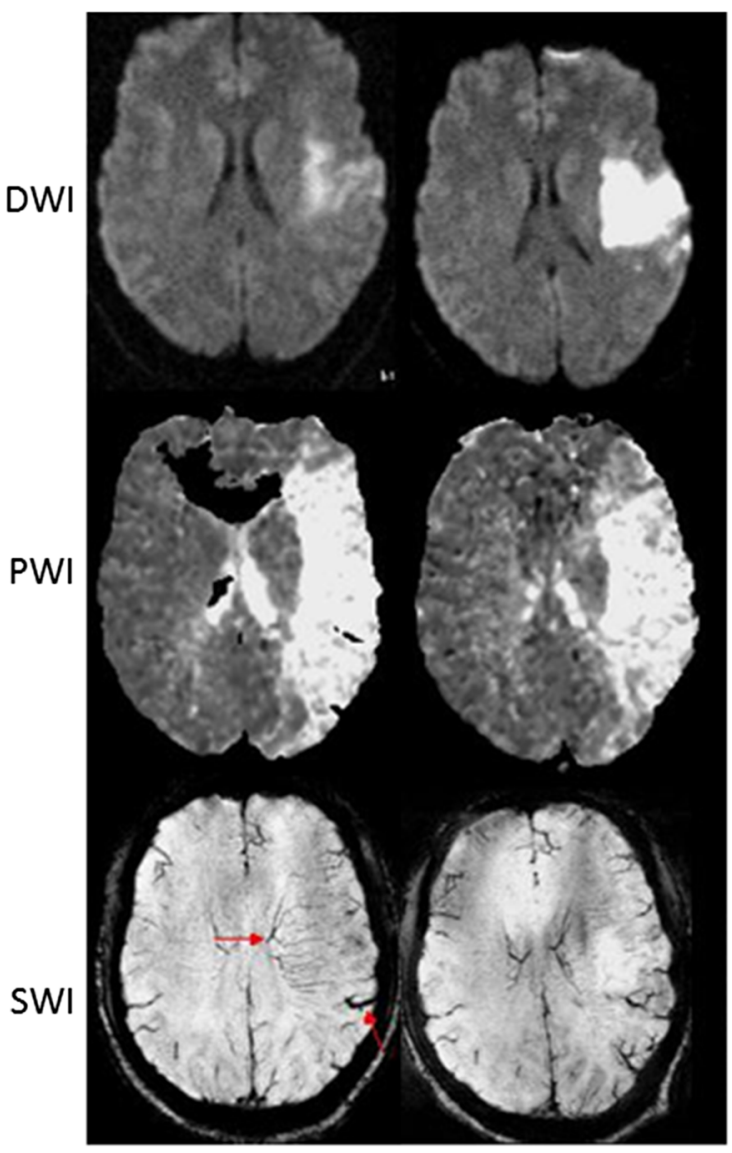

$5 \mathrm{hr}$

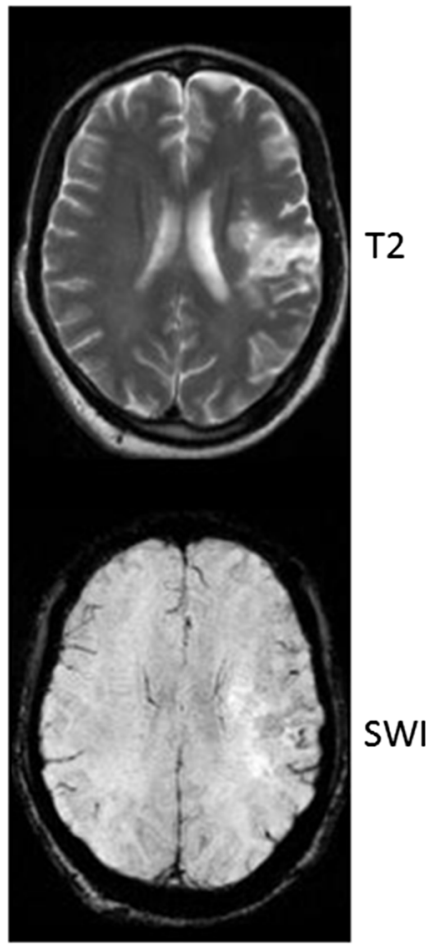

12 weeks
Susceptibility Weighted Imaging (SWI) in Acute Stroke

Paramagnetic $\mathrm{dHb}$ induces a phase difference between venous blood vessels and surrounding tissues, leading to a hypointense signal in venous vessels in high-resolution T2*-weighted images. Susceptibility-weighted imaging (SWI) is a high-resolution 3D gradient echo method in which hypointense magnitude vessel signal is enhanced using deoxyhemoglobin-induced phase shift [46]. When the blood oxygenation is altered, changes in the phase and visibility of these vessels can be detected in SWI images. An enhanced venous SWI signal may indicate a hypoxic state (low venous blood oxygenation) of the ischemic tissue. An example shown in Fig. 1 suggests that an enhanced SWI signal during acute ischemia may be a signature of atrisk but still viable tissue [47]. Using sequential scans acquired $<24 \mathrm{~h}, 2-3$ weeks and 2 months after stroke, a recent study has demonstrated that ischemia induced a greater SWI phase shift within veins near the stroke region and had little effect on the veins in the unaffected hemisphere [48•]. Moreover, the SWI phase changes (a marker for brain oxygenation change) over time across sequential scans correlated with NIHSS change over time, suggesting a dependence of clinical outcome on the tissue oxygenation level. While these results are encouraging, the SWI method does not provide measurements of brain oxygenation at the tissue level, but rather signal or phase changes within veins close to the ischemic tissue. Moreover, direct quantitative cerebral oxygenation has not been reported in acute stroke using the SWI method. More studies are needed to demonstrate the clinical utility of SWI for determining tissue viability in the acute setting of stroke.

\section{$\mathrm{R} 2$ or $\mathrm{T} 2 \mathrm{BOLD}$ Contrast}

The oxygenation dependence of $\mathrm{R} 2$ originates from the irreversible dephasing caused by water exchange and diffusion through the magnetic field gradient induced by deoxyhemoglobin. Using a Carr-Purcell-Meiboom-Gill (CPMG) sequence, Thulborn et al. [42] demonstrated that R2 (1/T2) of the blood increased along with the increase of the concentration of $\mathrm{dHb}$. Kavec et al. have demonstrated that a drop in CBF from $58 \pm 8$ to $17 \pm 3 \mathrm{ml} / 100 \mathrm{~g} / \mathrm{min}$ caused a shortening of $\mathrm{T} 2$ from $66.9 \pm 0.4$ to $64.6 \pm$ $0.5 \mathrm{~ms}$, without diffusion abnormality. The decreased T2 
(increased R2) suggested an elevated OEF during misery perfusion. In contrast, a moderately reduced $\mathrm{CBF}$ of $42 \pm 7 \mathrm{ml} / 100 \mathrm{~g} / \mathrm{min}$ did not induce a detectable T2 change [49]. Kettunen et al. [50] reported that a CBF below $20 \mathrm{ml} / 100 \mathrm{~g} / \mathrm{min}$ led to a decrease of T2 of $4.6 \pm 1.2$ and $6.8 \pm 1.7 \mathrm{~ms}$ after 7 and $15 \mathrm{~min}$ of ischemia, respectively, in a transient common carotid artery occlusion rat model. Other studies have demonstrated that T2 changes are reflected in a U-shaped curve $[1,51 \bullet, 52]$ as a function of CBF. Only moderately reduced CBF leads to decreased T2, while $\mathrm{T} 2$ increased in regions with severely reduced $\mathrm{CBF}$ $[51 \bullet, 52]$. Based on the pathophysiology of misery perfusion, a shortened $\mathrm{T} 2$ is expected but the U-shaped T2 change is unexpected. A plausible explanation of the observed T2 elevation in severe ischemia is vasogenic edema, which might occur very rapidly. Furthermore, the initial drop of $\mathrm{T} 2$ was followed by an increase in T2 after 30-60 min of stroke [53]. Vasogenic edema might also be the primary reason for the subsequently increased T2 following the initial reduced $\mathrm{T} 2$.

In summary, these studies suggested that the shortened T2 (or increased R2) shortly after ischemia may be caused by an increase of the local concentration of $\mathrm{dHb}$, which is consistent with the predicted physiology of misery perfusion. However, since T2 changes may depend on the brain oxygenation level as well as other pathophysiological processes such as vasogenic edema or inflammation, interpretation of the $\mathrm{T} 2$ changes in acute stroke may be very challenging. Moreover, since R2 is not as sensitive as $\mathrm{R} 2 *$ to the change of $\mathrm{dHb}$ concentration $[54,55]$, it is difficult to detect subtle cerebral oxygenation differences using R2-based methods.

\section{$\mathrm{R} 2 *$ or $\mathrm{T} 2 *$ BOLD Contrast}

In a simple way, $\mathrm{R} 2 *$ can be depicted as a summation of $\mathrm{R} 2$ and $\mathrm{R} 2^{\prime}\left(\mathrm{R} 2 *=\mathrm{R} 2+\mathrm{R} 2^{\prime}\right)$, where R2 (1/T2) and R2' $\left(1 / \mathrm{T} 2^{\prime}\right)$ are the irreversible and reversible relaxation rates, respectively. Signal decay caused by the $\mathrm{R} 2$ ' relaxation can be recovered in a spin echo. It has been demonstrated that R2* is more sensitive to the deoxyhemoglobin concentration change than R2 [54, 55]. Using a gradient echo (R2*) imaging approach, De Cresipgny et al. [56] have demonstrated a rapid signal drop upon MCAO occlusion and an overshoot after successful reperfusion in the cat brain. These findings suggest an initial increase followed by a decrease of $\mathrm{dHb}$ during acute ischemia and after reperfusion, respectively. In a rat focal ischemia model, areas of low $\mathrm{T} 2 *$ signal were larger than the regions with decreased diffusion [57], suggesting that regions with low T2* may encompass penumbral tissue. Furthermore, Tamura et al. used signals from dynamic susceptibility contrast imaging (DSC) before contrast arrival to demonstrate that the mean
T2*-weighted signal is significantly lower in the affected hemisphere in acute stroke patients [58•]. Similar MRI findings were also reported in two other patient studies [59, $60]$. It is postulated that the hypointense area may correspond to regions with elevated OEF under misery perfusion. However, a recent MR PET study [61•] found no significant relationship between the PET-measured OEF and MR T2*-weighted signal obtained from the precontrast arrival DSC signal. There are two plausible explanations for this discrepancy. First, background field inhomogeneities can cause an overestimation of $\mathrm{R} 2 *$ in focal regions that is not related to misery perfusion. Second, similar to $\mathrm{R} 2, \mathrm{R} 2 *\left(\mathrm{R} 2 *=\mathrm{R} 2+\mathrm{R} 2^{\prime}\right)$ can be affected by vasogenic edema.

\section{R2' BOLD Contrast}

$\mathrm{R} 2$ and R2* approaches are not specific and could be affected by numerous factors, including tissue oxygenation, brain edema or inflammation. In contrast, $\mathrm{R} 2^{\prime}$ is more directly related to the concentration of $\mathrm{dHb}$ and the volume fraction of $\mathrm{dHb}$ [62]. Therefore, it may be a better imaging biomarker for measuring OEF during acute ischemia. Geisler et al. examined R2' in regions with apparent diffusion coefficient (ADC) lesion growth (recruited in the final lesion but without acute ADC abnormality) and surviving tissue [63••]. They observed an elevated $\mathrm{R} 2^{\prime}$ in the ischemic hemisphere with the highest $\mathrm{R} 2^{\prime}$ in the acute ADC lesion, an increased but lower $\mathrm{R} 2^{\prime}$ in the region of lesion growth and the lowest $\mathrm{R} 2^{\prime}$ in surviving tissue regions. More recently, Siemonsen et al. reported that $\mathrm{R} 2^{\prime}>$ ADC mismatch can better predict infarct growth when compared to TTP $>$ ADC mismatch in patients treated with thrombolytics [64••]. Using a 1-h MCA occlusion monkey model, Zhang et al. [65] evaluated the temporal change of $\mathrm{R} 2{ }^{\prime}$ in the ischemic core (hyperintense signal in both acute DWI and 48-h T2w), penumbra (hyperintense signal in acute DWI without a 48-h T2w lesion) and oligemia (prolonged acute MTT with negative acute DWI and 48-h T2w) during MCAO and after reperfusion. Elevated R2 ${ }^{\prime}$ was detected in all three regions during $\mathrm{MCAO}$, suggesting a local $\mathrm{dHb}$ increase. After reperfusion, $\mathrm{R} 2^{\prime}$ decreased in the ischemic core, while it increased in both the penumbra and oligemia over time [65]. The persistently increased $\mathrm{R} 2{ }^{\prime}$ in the penumbra and oligemia after reperfusion is difficult to interpret. Of note, the definition of core/penumbra/oligemia in this study differs from the conventional definition of penumbra and oligemia in most of the DPM literature.

In summary, results based on the $\mathrm{R} 2^{\prime}$ methods are encouraging and may suggest clinical utility in acute stroke. However, since R2' may increase in all ischemic regions including the core, penumbra and oligemia (definitions varied among different studies), it remains unclear 
whether R2' alone will be useful in distinguishing an ischemic penumbra from core and oligemia. Similar to $\mathrm{R} 2 *, \mathrm{R} 2^{\prime}$ is affected by background field inhomogeneities. Careful system shimming and background susceptibility corrections are needed for an accurate representation of the $\mathrm{dHb}$ concentration.

\section{R2* Change After Oxygen Challenge}

Given the challenges associated with absolute measurements of $\mathrm{R} 2 *$ or $\mathrm{R} 2{ }^{\prime}$, relative $\mathrm{R} 2 *$ changes before and after oxygen challenge (OC) have been proposed to distinguish ischemic core, penumbra and oligemia. OC is achieved by inhalation of $100 \%$ oxygen under normobaric conditions. The use of $\Delta \mathrm{R} 2 *$ or $\Delta \mathrm{S}$ ( $\mathrm{S}$ is signal) before and after OC minimizes the effect of background field inhomogeneities. During OC, molecular oxygen may convert deoxyhemoglobin to oxyhemoglobin, therefore resulting in a signal increase in $\mathrm{T} 2 *$-weighted images (or decrease of $\Delta \mathrm{R} 2 *$ ). The hypothesis is that a high concentration of $\mathrm{dHb}$ in the penumbral tissue (suggestive of high OEF during misery perfusion) may lead to greater signal change in the penumbra. Santosh et al. [66] reported signal increases of 1.8, 3.7 and $0.24 \%$ in the contralateral cortex, region of DPM and ADC-defined ischemic core, respectively, using a permanent MCA occlusion (pMCAO) rat model. In another study, $\left[{ }^{14} \mathrm{C}\right] 2$ - deoxyglucose (2-DG) autoradiography was used in combination with $\mathrm{T} 2 *$ OC MR to determine the glucose metabolic status of various regions [67]. The ischemic core showed low T2* OC signal change and low glucose utilization as demonstrated in 2-DG images. In regions with increased $\mathrm{T} 2 *$ signal during $\mathrm{OC}$, a normal glucose metabolism similar to that of the contralateral hemisphere was found. In addition, a hyperglycolytic band was detected within the ADC lesion. A small T2* OC signal change lower than that from the contralateral hemisphere was obtained in this hyperglycolytic band. Similar T2* signal changes resulting from OC were found in rats following pMCAO [68]. Using a transient MCA occlusion (tMCAO) rat model, Robertson et al. [69] examined the $\mathrm{T} 2 *$ signal response to $\mathrm{OC}$ during ischemia, immediately and 7 days after reperfusion. In this study, the ischemic core and penumbra were defined in regions with low (core) or high (penumbra) T2* OC responses during ischemia, respectively. They found that the $\mathrm{T} 2 * \mathrm{OC}$ response remained low in the core before and after reperfusion. The ischemic core infarcted 7 days after reperfusion. The contralateral hemisphere had consistently moderate $\mathrm{T} 2 *$ signal change during ischemia and after reperfusion. In contrast, penumbra had an elevated T2* OC response during ischemia but then a decreased $\mathrm{OC}$ response upon reperfusion. The OC-defined penumbra (high OC response during ischemia) was not recruited into the final infarct. A more recent study reported a different OC response evolution in core regions (defined in regions with low OC response during ischemia) after reperfusion in rats undergoing a tMCAO [70]. In this study, the core regions had low OC during ischemia, but high OC responses after reperfusion. Since most of the core regions became infarcted, this suggests that high OC responses, if used alone, do not necessarily reflect salvageable tissue.

Dani et al. [71••] have reported the first clinical stroke application of the OC approach. Thirty-five stroke patients with a median onset time of $18 \mathrm{~h}$ were recruited. Data from 18 patients who had reasonable $\mathrm{T} 2 *$ signal time curves in the unaffected hemishpere were included in the analysis. T2* OC signal curves were evaluated in the presumed ischemic core (defined by abnormal ADC), ischemic penumbra (perfusion-diffusion mismatch or expanded ADC lesion at day 3) and contralateral hemisphere. In general, the DWI-defined core showed a reduced OC response as compared to contralateral tissue, while the presumed penumbra in patients who were imaged acutely $(<8 \mathrm{~h})$ showed a trend of greater $\mathrm{OC}$ responses. However, a large variation in OC responses was observed across patients. Ten, 4 and 3 out of 17 DWI core lesions showed positive, flat and negative OC responses, while 5, 1 and 2 out of 8 penumbra lesions showed positive, flat and negative OC responses, respectively. Moreover, there was poor spatial correspondence between the DPM-defined penumbra and regions with high OC responses in most of the patient examples shown in [71••]. The subpar performance of this OC approach in clinical stroke is not surprising, given that stroke patients have much greater variations in hemodynamics and the elapsed times after stroke onset compared to the experimental MCAO in animal models.

In summary, encouraging results have been reported that potentially distinguish core, penumbra and normal tissues using the $\mathrm{T} 2 *$ signal change to $\mathrm{OC}$, particularly in experimental MCAO. Since several factors including $\mathrm{CBV}$, $\mathrm{CBF}$, reperfusion status, reperfusion time and $\mathrm{T} 1$ change (due to an elevated level of dissolved $\mathrm{O}_{2}$ in blood during OC) may all affect the OC responses in human stroke; therefore, it is challenging to use simple OC response thresholds to separate penumbra from core, oligemia and normal tissues without considering these other factors. The advantages of this OC approach include (1) the reduced confounding influence of background susceptibility and (2) wide availability in most clinical centers by using a standard $\mathrm{T} 2 *$ MR pulse sequence.

\section{MR_OEF and MR_OMI}

All the aforementioned methods using the SWI, R2*, R2, $\mathrm{R} 2$ ' or $\mathrm{R} 2 *$ with $\mathrm{OC}$ are indirect measurements of tissue oxygenation, which may be subject to other factors that are 
irrelevant to tissue metabolic activities. On the other hand, as suggested by the PET literature, OEF and $\mathrm{CMRO}_{2}$ can provide a more direct assessment of tissue viability and therefore may be better imaging biomarkers for penumbral imaging.

Extensive efforts have focused on measuring brain OEF and $\mathrm{CMRO}_{2}$ using $\mathrm{MR}$ approaches at the whole brain (global) level or at the regional level. Since whole brain global measurements have little utility in focal ischemia, we will only review MR approaches for measuring regional OEF that have shown promises in stroke. As suggested by the quantitative BOLD (qBOLD) biophysical signal models $[72,73], \mathrm{R} 2{ }^{\prime}$ is proportional to the product of the concentration of $\mathrm{dHb}$ and the venous cerebral blood volume (vCBV). Regional cerebral venous oxygen saturation $\left(\mathrm{SvO}_{2}\right)$ or OEF $\left(\mathrm{SaO}_{2}-\mathrm{SvO}_{2}\right)$ can be measured if both $\mathrm{R} 2^{\prime}$ and $\mathrm{VCBV}$ can be acquired. Using either a gradient echo sampled spin echo $[73,74]$ or an asymmetric spin echo EPI sequences (ASE) [75], PET comparable OEF was obtained from normal subjects under both normal and hypercapnic conditions [74-76]. MR-measured cerebral oxygen saturation has been validated against gold standard blood gas analysis for a wide range of oxygen saturations $(0.1-0.8)$ in rats under moderate, severe hypoxic, hypercapnic and normal control states [77••]. Similarly, good correlation between the MR measured oxygen saturation and blood gas oximetry was obtained in an $\mathrm{SvO}_{2}$ range of $0.45-0.85$ induced by two different anesthetic conditions using isoflurane and alpha-chloralose anesthesia [78]. Moreover, using multiple MR scans to estimate R2*, R2 and CBV separately, Christen et al. [79] demonstrated that MRmeasured $\mathrm{SvO}_{2}$ correlated well with blood gas oximetry results in rats under hyperoxia and hypoxia. Of note, the arterial-venous oxygen difference was also the same gold standard by which PET-OEF was validated $[80,81]$.

BOLD-based MR_OEF methods measure susceptibility, a parameter related to the concentration of $\mathrm{dHb}$, and infer oxygen extraction fraction from this measurement assuming that $\mathrm{SaO}_{2}$ in large arteries and arterioles is at $100 \%$ even during focal ischemia. Since both OEF and vCBV affect the MR signal, an accurate measurement of vCBV is needed in order to obtain OEF. A high signal-to-noise ratio (SNR) is usually required [82, 83]. MR_OEF has been measured in healthy human subjects under both normal and hypercapnic conditions, and values are closely comparable to those reported using PET [67]. Moreover, global validation of MR_OEF has been performed in animals [78, 79, 84]. However, regional MR_OEF measurement has not been validated against simultaneous PET OEF under pathophysiological conditions.

MR-derived oxygen metabolism can be computed as a product of MR_OEF and CBF. This parameter was first termed as MR_CMRO 2 [76] to distinguish it from the PET
$\mathrm{CMRO}_{2}$ (defined as $\mathrm{OEF} \times \mathrm{CBF} \times \mathrm{CaO}_{2}$ ). The 'MRderived cerebral oxygen metabolic index' (MR_COMI or simply MROMI) has since been utilized [77••].

CBF can be obtained using either DSC [85] or arterial spin labeling (ASL) [86-88] methods. The DSC approach requires the injection of a contrast agent, while the ASL approach uses magnetically labeled arterial blood to derive CBF. The DSC method is widely utilized in clinical stroke because of its speed and good SNR. However, absolute CBF measurement based on DSC is very challenging. In contrast, ASL methods provide absolute CBF measurement but with a much lower SNR.

MROMI has been used to depict temporal evolution of cerebral oxygen metabolism during cerebral ischemia in rats subject to tMCAO [77••]. In this focal ischemia study, MROMI values were lowest within the infarct, while the surviving peri-infarct region showed moderately reduced MROMI. MROMI within the region of ischemia evolved in space and time. Ischemic regions with severely reduced MROMI (presumed core) continued to expand while regions with moderately reduced MROMI (presumed penumbra) decreased in size over time. These observations suggested that the metabolically active penumbra evolves into the infracted core as time progresses.

The potential clinical utility of MROMI was first evaluated in seven acute stroke patients [89]. Normalized MROMI values were $0.40 \pm 0.24$ and $0.55 \pm 0.11$ of the contralateral hemisphere in the final infarct and the DPM regions, respectively, in agreement with previous PET measurements in stroke patients [25].

To test the clinical utility of MROMI, a prospective imaging study was undertaken. Forty acute stroke patients were serially imaged $3.0 \mathrm{~h}$ (tp1), $6.2 \mathrm{~h}$ (tp2) and 1 month (tp3) after symptom onset [90••]. CBF was determined using DSC and OEF was obtained using the ASE method; MROMI was computed as the product of CBF and OEF. In the tp1 MRI (obtained within $3 \mathrm{~h}$ of stroke onset) regions with very low MROMI values predicted eventual infarction of tissue as demonstrated on the 1-month FLAIR image. To further investigate whether MROMI can be utilized to delineate the ischemic penumbra, a quantitative analysis was designed to find threshold values that optimally segregated tissue into core, penumbra and oligemia, based on ideal infarct probabilities. In theory, the infarct probability (IP) for tissue in the core is $100 \%$; for non-reperfused penumbra, $100 \%$; for reperfused penumbra, $0 \%$; for oligemic tissue, $0 \%$. Average prediction error (APE, averaged difference between the actual IP and ideal IP across the four tissue groups) was utilized to choose an optimal pair of MROMI thresholds to define core, penumbra and oligemia [91••]. A pair of optimal DPM thresholds was also derived through a similar process so that DPM thresholds could be compared directly to OMI thresholds for their 
ability to predict reperfusion-dependent infarction. We found that the MROMI outperformed DPM in predicting reperfusion-dependent infarction (minimizing APE) in this cohort of patients $[92 \cdot \bullet]$.

In summary, preliminary results supporting the use of MROMI for penumbral imaging are encouraging. MROMI requires the measurement of both $\mathrm{OEF}$ and $\mathrm{CBF}$, in addition to tissue segmentation, which is required for normalization to minimize its dependence on tissue type. In addition, a custom sequence was utilized for the measurement of OEF. The complex imaging acquisition and data analysis have made the method sensitive to noise and imaging artifacts. A robust, rapid and streamlined data acquisition and postprocessing method will improve the clinical utility of this technique. Furthermore, validation of regional measurement of MROEF and MROMI by direct comparison against PET measurement is needed, especially in patients with focal lesions. Since hemodynamic changes occur rapidly during hyperacute stroke, an integrated MR/PET system that allows simultaneous acquisition will be valuable for this validation.

\section{Conclusions}

Noninvasive approaches providing information on tissue viability during acute ischemic stroke have been extensively pursued. In this review, we introduce several MR BOLD imaging approaches to directly or indirectly measure tissue oxygenation and oxygen metabolism. While results are encouraging, further technical refinement and validation in patients are warranted to fully test whether these techniques can be translated for clinical use in acute ischemic stroke.

Acknowledgments This study was supported in part by grants from the National Institute of Health (NIH 5R01NS054079, NIH 5P50NS055977) and American Heart Association (AHA 0730321N).

\section{Compliance with Ethics Guidelines}

Conflict of Interest Hongyu An, Andria L. Ford, Katie D. Vo, Qingwei Liu, Yasheng Chen, Jin-Moo Lee and Weili Lin declare that they have no conflicts of interest.

Human and Animal Rights and Informed Consent This article does not contain any studies with human or animal subjects performed by the authors.

\section{References}

Papers of particular interest, published recently, have been highlighted as:

- Of importance

•- Of significant importance
1. Hacke W, Donnan G, Fieschi C, Kaste M, von Kummer R, Broderick JP, Brott T, Frankel M, Grotta JC, Haley EC Jr, Kwiatkowski T, Levine SR, Lewandowski C, Lu M, Lyden P, Marler JR, Patel S, Tilley BC, Albers G, Bluhmki E, Wilhelm M, Hamilton S. Association of outcome with early stroke treatment: Pooled analysis of ATLANTIS, ECASS, and NINDS rt-PA stroke trials. Lancet. 2004;363:768-74.

2. Astrup J, Symon L, Branston NM, Lassen NA. Cortical evoked potential and extracellular $\mathrm{k}+$ and $\mathrm{h}+$ at critical levels of brain ischemia. Stroke. 1977;8:51-7.

3. Astrup J. Energy-requiring cell functions in the ischemic brain. Their critical supply and possible inhibition in protective therapy. J Neurosurg. 1982;56:482-97.

4. The NINDS rt-PA Stroke Study Group. Tissue plasminogen activator for acute ischemic stroke. N Engl J Med. 1995;333:1581-7.

5. Hacke W, Kaste M, Bluhmki E, Brozman M, Davalos A, Guidetti D, Larrue V, Lees KR, Medeghri Z, Machnig T, Schneider D, von Kummer R, Wahlgren N, Toni D. Thrombolysis with alteplase 3-4.5 h after acute ischemic stroke. N Engl J Med. 2008;359: $1317-29$

6. Hacke W, Kaste M, Fieschi C, Toni D, Lesaffre E, von Kummer R, Boysen G, Bluhmki E, Hoxter G, Mahagne MH. Intravenous thrombolysis with recombinant tissue plasminogen activator for acute hemispheric stroke. The European Cooperative Acute Stroke Study (ECASS). JAMA. 1995;274:1017-25.

7. Hacke W, Kaste M, Fieschi C, von Kummer R, Davalos A, Meier D, Larrue V, Bluhmki E, Davis S, Donnan G, Schneider D, DiezTejedor E, Trouillas P. Randomised double-blind placebo-controlled trial of thrombolytic therapy with intravenous alteplase in acute ischaemic stroke (ECASS ii). Second European-Australasian acute stroke study investigators. Lancet. 1998;352:1245-51.

8. Clark WM, Wissman S, Albers GW, Jhamandas JH, Madden KP, Hamilton S. Recombinant tissue-type plasminogen activator (alteplase) for ischemic stroke 3-5 h after symptom onset. The ATLANTIS study: a randomized controlled trial. Alteplase thrombolysis for acute noninterventional therapy in ischemic stroke. JAMA. 1999;282:2019-26.

9. Donnan GA, Howells DW, Markus R, Toni D, Davis SM. Can the time window for administration of thrombolytics in stroke be increased? CNS Drugs. 2003;17:995-1011.

10. Adeoye O, Hornung R, Khatri P, Kleindorfer D. Recombinant tissue-type plasminogen activator use for ischemic stroke in the united states: A doubling of treatment rates over the course of 5 years. Stroke. 2011;42:1952-5.

11. Kidwell CS, Jahan R, Gornbein J, Alger JR, Nenov V, Ajani Z, Feng L, Meyer BC, Olson S, Schwamm LH, Yoo AJ, Marshall RS, Meyers PM, Yavagal DR, Wintermark M, Guzy J, Starkman S, Saver JL. A trial of imaging selection and endovascular treatment for ischemic stroke. New Engl J Med. 2013;368:914-23.

12. Saver JL, Jahan R, Levy EI, Jovin TG, Baxter B, Nogueira RG, Clark W, Budzik R, Zaidat OO. Solitaire flow restoration device versus the merci retriever in patients with acute ischaemic stroke (SWIFT): a randomised, parallel-group, non-inferiority trial. Lancet. 2012;380:1241-9.

13. Fisher M, Takano K. The penumbra, therapeutic time window and acute ischaemic stroke. Baillieres Clin Neurol. 1995;4:279-95.

14. Albers GW, Thijs VN, Wechsler L, Kemp S, Schlaug G, Skalabrin E, Bammer R, Kakuda W, Lansberg MG, Shuaib A, Coplin W, Hamilton S, Moseley M, Marks MP. Magnetic resonance imaging profiles predict clinical response to early reperfusion: the diffusion and perfusion imaging evaluation for understanding stroke evolution (DEFUSE) study. Ann Neurol. 2006;60:508-17.

15. Davis SM, Donnan GA. Advances in penumbra imaging with MR. Cerebrovasc Dis. 2004;17(Suppl 3):23-7.

16. Davis SM, Donnan GA, Parsons MW, Levi C, Butcher KS, Peeters A, Barber PA, Bladin C, De Silva DA, Byrnes G, Chalk JB, 
Fink JN, Kimber TE, Schultz D, Hand PJ, Frayne J, Hankey G, Muir K, Gerraty R, Tress BM, Desmond PM. Effects of alteplase beyond $3 \mathrm{~h}$ after stroke in the echoplanar imaging thrombolytic evaluation trial (EPITHET): a placebo-controlled randomised trial. Lancet Neurol. 2008;7:299-309.

17. Kidwell CS, Alger JR, Saver JL. Beyond mismatch: evolving paradigms in imaging the ischemic penumbra with multimodal magnetic resonance imaging. Stroke. 2003;34:2729-35.

18. Li F, Liu KF, Silva MD, Omae T, Sotak CH, Fenstermacher JD, Fisher M, Hsu CY, Lin W. Transient and permanent resolution of ischemic lesions on diffusion-weighted imaging after brief periods of focal ischemia in rats: correlation with histopathology. Stroke. 2000;31:946-54.

19. Li F, Silva MD, Liu KF, Helmer KG, Omae T, Fenstermacher JD, Sotak CH, Fisher M. Secondary decline in apparent diffusion coefficient and neurological outcomes after a short period of focal brain ischemia in rats. Ann Neurol. 2000;48:236-44.

20. Li F, Silva MD, Sotak CH, Fisher M. Temporal evolution of ischemic injury evaluated with diffusion-, perfusion-, and $\mathrm{T}^{\wedge} 2$ weighted MRI. Neurology. 2000;54:689-96.

21. Kidwell CS, Alger JR, Di Salle F, Starkman S, Villablanca P, Bentson J, Saver JL. Diffusion MRI in patients with transient ischemic attacks. Stroke. 1999;30:1174-80.

22. Kidwell CS, Saver JL, Mattiello J, Starkman S, Vinuela F, Duckwiler G, Gobin YP, Jahan R, Vespa P, Kalafut M, Alger JR. Thrombolytic reversal of acute human cerebral ischemic injury shown by diffusion/perfusion magnetic resonance imaging. Ann Neurol. 2000;47:462-9.

23. Heiss WD, Sobesky J. Comparison of PET and DW/PW-MRI in acute ischemic stroke. Keio J Med. 2008;57:125-31.

24. Sobesky J, Zaro Weber O, Lehnhardt FG, Hesselmann V, Neveling M, Jacobs A, Heiss WD. Does the mismatch match the penumbra? Magnetic resonance imaging and positron emission tomography in early ischemic stroke. Stroke. 2005;36:980-5.

25. Powers WJ, Grubb RL Jr, Darriet D, Raichle ME. Cerebral blood flow and cerebral metabolic rate of oxygen requirements for cerebral function and viability in humans. J Cereb Blood Flow Metab. 1985;5:600-8.

26. Frykholm P, Andersson JL, Valtysson J, Silander HC, Hillered L, Persson L, Olsson Y, Yu WR, Westerberg G, Watanabe Y, Langstrom B, Enblad P. A metabolic threshold of irreversible ischemia demonstrated by PET in a middle cerebral artery occlusion-reperfusion primate model. Acta Neurol Scand. 2000;102:18-26.

27. Young AR, Sette G, Touzani O, Rioux P, Derlon JM, MacKenzie ET, Baron JC. Relationships between high oxygen extraction fraction in the acute stage and final infarction in reversible middle cerebral artery occlusion: an investigation in anesthetized baboons with positron emission tomography. J Cereb Blood Flow Metab. 1996;16:1176-88.

28. Giffard C, Young AR, Kerrouche N, Derlon JM, Baron JC. Outcome of acutely ischemic brain tissue in prolonged middle cerebral artery occlusion: a serial positron emission tomography investigation in the baboon. J Cereb Blood Flow Metab. 2004;24:495-508.

29. Powers WJ, Press GA, Grubb RL, Gado M, Raichle ME. The effect of hemodynamically significant carotid artery disease on the hemodynamic status of the cerebral circulation. Ann Intern Med. 1987;106:27-34

30. Powers WJ, Raichle ME. Positron emission tomography and its application to the study of cerebrovascular disease in man. Stroke. 1985;16:361-76.

31. Derdeyn CP, Videen TO, Yundt KD, Fritsch SM, Carpenter DA, Grubb RL, Powers WJ. Variability of cerebral blood volume and oxygen extraction: stages of cerebral haemodynamic impairment revisited. Brain. 2002;125:595-607.
32. MacKenzie ET, McGeorge AP, Graham DI, Fitch W, Edvinsson L, Harper AM. Effects of increasing arterial pressure on cerebral blood flow in the baboon: influence of the sympathetic nervous system. Pflugers Arch. 1979;378:189-95.

33. Rapela CE, Green HD. Autoregulation of canine cerebral blood flow. Circ Res. 1964;15(SUPPL):205-12.

34. Powers WJ. Cerebral hemodynamics in ischemic cerebrovascular disease. Ann Neurol. 1991;29:231-40.

35. Baron JC, Bousser MG, Comar D, Soussaline F, Castaigne P. Noninvasive tomographic study of cerebral blood flow and oxygen metabolism in vivo. Potentials, limitations, and clinical applications in cerebral ischemic disorders. Eur Neurol. 1981;20:273-84.

36. Heiss WD, Sobesky J, Hesselmann V. Identifying thresholds for penumbra and irreversible tissue damage. Stroke. 2004;35: 2671-4.

37. Baron JC. Mapping the ischaemic penumbra with PET: implications for acute stroke treatment. Cerebrovasc Dis. 1999;9:193-201.

38. Guadagno JV, Jones PS, Fryer TD, Barret O, Aigbirhio FI, Carpenter TA, Price CJ, Gillard JH, Warburton EA, Baron JC. Local relationships between restricted water diffusion and oxygen consumption in the ischemic human brain. Stroke. 2006;37:1741-8.

39. Heiss WD, Huber M, Fink GR, Herholz K, Pietrzyk U, Wagner $\mathrm{R}$, Wienhard K. Progressive derangement of periinfarct viable tissue in ischemic stroke. J Cereb Blood Flow Metab. 1992;12: 193-203.

40. Baron JC. Pathophysiology of acute cerebral ischemia: PET studies in humans. Cerebrovasc Dis. 1991;1:22-31.

41. Pauling L, Coryell CD. The magnetic properties and structure of hemoglobin, oxyhemoglobin and carbonmonoxyhemoglobin. Proc Natl Acad Sci USA. 1936;22:210-6.

42. Thulborn KR, Waterton JC, Matthews PM, Radda GK. Oxygenation dependence of the transverse relaxation time of water protons in whole blood at high field. Biochim Biophys Acta. 1982;714:265-70.

43. Ogawa S, Lee TM, Kay AR, Tank DW. Brain magnetic resonance imaging with contrast dependent on blood oxygenation. Proc Natl Acad Sci USA. 1990;87:9868-72.

44. Ogawa S, Lee TM, Barrere B. The sensitivity of magnetic resonance image signals of a rat brain to changes in the cerebral venous blood oxygenation. Magn Reson Med. 1993;29:205-10.

45. Ogawa S, Menon RS, Tank DW, Kim SG, Merkle H, Ellermann JM, Ugurbil K. Functional brain mapping by blood oxygenation level-dependent contrast magnetic resonance imaging. A comparison of signal characteristics with a biophysical model. Biophys J. 1993;64:803-12.

46. Haacke EM, Xu Y, Cheng YC, Reichenbach JR. Susceptibility weighted imaging (swi). Magnetic resonance in medicine: official journal of the Society of Magnetic Resonance in Medicine/ Society of Magnetic Resonance in Medicine. 2004;52:612-8.

47. An H, Liu Q, Chen Y, Vo KD, Ford AL, Lee JM, Lin W. Oxygen metabolism in ischemic stroke using magnetic resonance imaging. Transl Stroke Res. 2012;3:65-75.

48. • Li M, Hu J, Miao Y, Shen H, Tao D, Yang Z, Li Q, Xuan SY, Raza W, Alzubaidi S, Haacke EM. In vivo measurement of oxygenation changes after stroke using susceptibility weighted imaging filtered phase data. PLoS One. 2013;8:e63013. A SWI study to demonstrate the phase changes over time across sequential scans correlate with NIHSS change over time, suggesting a dependence of clinical outcome on the tissue oxygenation level.

49. Kavec M, Grohn OH, Kettunen MI, Silvennoinen MJ, Penttonen M, Kauppinen RA. Use of spin echo T(2) BOLD in assessment of cerebral misery perfusion at $1.5 \mathrm{~T}$. Magma. 2001;12:32-9.

50. Kettunen MI, Grohn OH, Silvennoinen MJ, Penttonen M, Kauppinen RA. Quantitative assessment of the balance between oxygen delivery and consumption in the rat brain after transient 
ischemia with T2-BOLD magnetic resonance imaging. J Cereb Blood Flow Metab. 2002;22:262-70.

51. - Grohn OH, Kettunen MI, Penttonen M, Oja JM, van Zijl PC, Kauppinen RA. Graded reduction of cerebral blood flow in rat as detected by the nuclear magnetic resonance relaxation time T2: A theoretical and experimental approach. J Cereb Blood Flow Metab. 2000;20:316-326. T2-based BOLD was used to reveal that moderately reduced $C B F$ leads to decreased $T 2$, while $T 2$ increased in regions with severely reduced $C B F$.

52. Grohn $\mathrm{OH}$, Kauppinen RA. Assessment of brain tissue viability in acute ischemic stroke by BOLD MRI. NMR Biomed. 2001;14: 432-40.

53. Grohn OH, Lukkarinen JA, Oja JM, van Zijl PC, Ulatowski JA, Traystman RJ, Kauppinen RA. Noninvasive detection of cerebral hypoperfusion and reversible ischemia from reductions in the magnetic resonance imaging relaxation time, T2. J Cereb Blood Flow Metab. 1998;18:911-20.

54. Boxerman JL, Hamberg LM, Rosen BR, Weisskoff RM. MR contrast due to intravascular magnetic susceptibility perturbations. Magn Reson Med. 1995;34:555-66.

55. Bandettini PA, Wong EC, Jesmanowicz A, Hinks RS, Hyde JS. Spin-echo and gradient-echo EPI of human brain activation using BOLD contrast: a comparative study at $1.5 \mathrm{~T}$. NMR Biomed. 1994;7:12-20.

56. De Crespigny AJ, Wendland MF, Derugin N, Kozniewska E, Moseley ME. Real-time observation of transient focal ischemia and hyperemia in cat brain. Magnetic Reson Med. 1992;27: 391-7.

57. Roussel SA, van Bruggen N, King MD, Gadian DG. Identification of collaterally perfused areas following focal cerebral ischemia in the rat by comparison of gradient echo and diffusionweighted MRI. J Cereb Blood Flow Metab. 1995;15:578-86.

58. - Tamura H, Hatazawa J, Toyoshima H, Shimosegawa E, Okudera T. Detection of deoxygenation-related signal change in acute ischemic stroke patients by $\mathrm{T} 2 *$-weighted magnetic resonance imaging. Stroke, a journal of cerebral circulation. 2002;33: 967-971. This study demonstrated reduced $T 2 * B O L D$ within ischemia.

59. Wardlaw JM, von Heijne A. Increased oxygen extraction demonstrated on gradient echo $(\mathrm{T} 2 *)$ imaging in a patient with acute ischaemic stroke. Cerebrovasc Dis. 2006;22:456-8.

60. Morita N, Harada M, Uno M, Matsubara S, Matsuda T, Nagahiro $\mathrm{S}$, Nishitani $\mathrm{H}$. Ischemic findings of $\mathrm{T} 2 *$-weighted 3-Tesla MRI in acute stroke patients. Cerebrovasc Dis. 2008;26:367-75.

61. Donswijk ML, Jones PS, Guadagno JV, Carpenter TA, Moustafa RR, Fryer TD, Aigbirhio FI, Warburton EA, Baron JC. T2*-weighted MRI versus oxygen extraction fraction PET in acute stroke. Cerebrovasc Dis. 2009;28:306-313. A direct comparison between $T 2 *$ BOLD and OEF measured using PET in acute stroke patients.

62. Yablonskiy DA. Quantitation of intrinsic magnetic susceptibilityrelated effects in a tissue matrix. Phantom study. Magn Reson Med. 1998;39:417-28.

63. •• Geisler BS, Brandhoff F, Fiehler J, Saager C, Speck O, Rother J, Zeumer H, Kucinski T. Blood-oxygen-level-dependent MRI allows metabolic description of tissue at risk in acute stroke patients. Stroke. 2006;37:1778-1784. Elevated R2' was dected in the ischemic hemisphere with the highest $R 2^{\prime}$ in $A D C$ lesions, an increased $R 2^{\prime}$ but to a lesser degree in the lesion growth region and smallest $R 2^{\prime}$ in surviving tissue regions.

64. • Siemonsen S, Fitting T, Thomalla G, Horn P, Finsterbusch J, Summers P, Saager C, Kucinski T, Fiehler J. T2' imaging predicts infarct growth beyond the acute diffusion-weighted imaging lesion in acute stroke. Radiology. 2008;248:979-986. $R 2^{\prime}>A D C$ mismatch can better predict infarct growth when compared to TTP $>A D C$ mismatch in thrombolytic treated patients.
65. Zhang J, Chen YM, Zhang YT. Blood-oxygenation-leveldependent-(BOLD-) based R2' MRI study in monkey model of reversible middle cerebral artery occlusion. J Biomed Biotechnol. 2011;2011:318346.

66. Santosh C, Brennan D, McCabe C, Macrae IM, Holmes WM, Graham DI, Gallagher L, Condon B, Hadley DM, Muir KW, Gsell W. Potential use of oxygen as a metabolic biosensor in combination with $\mathrm{T} 2 *$-weighted MRI to define the ischemic penumbra. J Cereb Blood Flow Metab. 2008;28:1742-53.

67. An H, Sen S, Chen Y, Powers WJ, Lin W. Noninvasive measurements of cerebral blood flow, oxygen extraction fraction, and oxygen metabolic index in human with inhalation of air and carbogen using magnetic resonance imaging. Transl Stroke Res. 2012;3:246-54.

68. Shen Q, Huang S, Du F, Duong TQ. Probing ischemic tissue fate with BOLD fMRI of brief oxygen challenge. Brain Res. 2011; 1425:132-41

69. Hu B, An HM, Shen KP, Song HY, Deng S. Polygonum cuspidatum extract induces anoikis in hepatocarcinoma cells associated with generation of reactive oxygen species and downregulation of focal adhesion kinase. Evid Based Complem Altern Med. 2012;2012:607675.

70. Shen Q, Du F, Huang S, Duong TQ. Effects of cerebral ischemic and reperfusion on $\mathrm{T}^{*}$-weighted MRI responses to brief oxygen challenge. J Cereb Blood Flow Metab. 2013.

71. • Dani KA, Santosh C, Brennan D, McCabe C, Holmes WM, Condon B, Hadley DM, Macrae IM, Shaw M, Muir KW. $\mathrm{T} 2 *$-weighted magnetic resonance imaging with hyperoxia in acute ischemic stroke. Ann neurol. 2010;68:37-47. This study is the first application of the $T 2 *$ under oxygen challenge $(O C)$ in clinical stroke. The DWI-defined lesion showed a reduced OC response as compared to contralateral tissue, while the presumed penumbra, imaged acutely, showed a trend of greater OC responses.

72. Yablonskiy DA, Haacke EM. Theory of NMR signal behavior in magnetically inhomogeneous tissues: the static dephasing regime. Magn Reson Med. 1994;32:749-63.

73. He X, Yablonskiy DA. Quantitative BOLD: mapping of human cerebral deoxygenated blood volume and oxygen extraction fraction: default state. Magn Reson Med. 2007;57:115-26.

74. An H, Lin W. Quantitative measurements of cerebral blood oxygen saturation using magnetic resonance imaging. J Cereb Blood Flow Metab. 2000;20:1225-36.

75. An H, Lin W. Impact of intravascular signal on quantitative measures of cerebral oxygen extraction and blood volume under normo- and hypercapnic conditions using an asymmetric spin echo approach. Magn Reson Med. 2003;50:708-16.

76. An H, Lin W. Cerebral oxygen extraction fraction and cerebral venous blood volume measurements using magnetic resonance imaging: effects of magnetic field variation. Magn Reson Med. 2001;47:958-66.

77. •• An H, Liu Q, Chen Y, Lin W. Evaluation of MR-derived cerebral oxygen metabolic index in experimental hyperoxic hypercapnia, hypoxia, and ischemia. Stroke. 2009;40:2165-2172. MROMI was used to depict the temporal evolution of cerebral oxygen metabolism during cerebral ischemia in rats subject to tMCAO.

78. He X, Zhu M, Yablonskiy DA. Validation of oxygen extraction fraction measurement by qBOLD technique. Magn Reson Med. 2008;60:882-8.

79. Christen T, Lemasson B, Pannetier N, Farion R, Segebarth C, Remy C, Barbier EL. Evaluation of a quantitative blood oxygenation level-dependent (qBOLD) approach to map local blood oxygen saturation. NMR Biomed. 2010;25(12):1340-8.

80. Altman DI, Lich LL, Powers WJ. Brief inhalation method to measure cerebral oxygen extraction fraction with PET: accuracy 
determination under pathologic conditions. J Nucl Med. 1991;32: $1738-41$.

81. Hattori N, Bergsneider M, Wu HM, Glenn TC, Vespa PM, Hovda DA, Phelps ME, Huang SC. Accuracy of a method using short inhalation of (15)o-o(2) for measuring cerebral oxygen extraction fraction with PET in healthy humans. J Nucl Med. 2004;45:765-70.

82. Sohlin MC, Schad LR. Susceptibility-related MR signal dephasing under nonstatic conditions: experimental verification and consequences for qBOLD measurements. JMRI. 2011;33:417-25.

83. Sedlacik J, Reichenbach JR. Validation of quantitative estimation of tissue oxygen extraction fraction and deoxygenated blood volume fraction in phantom and in vivo experiments by using MRI. Magn Reson Med. 2010;63:910-21.

84. An H, Liu Q, Chen Y, Lin W. Evaluation of mr-derived cerebral oxygen metabolic index in experimental hyperoxic hypercapnia, hypoxia, and ischemia. Stroke. 2009;40:2165-72.

85. Rosen BR, Turner R, Hunter GJ, Fordham JA. MR depicts perfusion of brain and heart. Diagn Imaging (San Franc). 1991;13:105-10.

86. Alsop DC, Detre JA. Reduced transit-time sensitivity in noninvasive magnetic resonance imaging of human cerebral blood flow. J Cereb Blood Flow Metab. 1996;16:1236-49.

87. Wong EC, Buxton RB, Frank LR. Quantitative perfusion imaging using arterial spin labeling. Neuroimaging Clin N Am. 1999;9: $333-42$.
88. Detre JA, Samuels OB, Alsop DC, Gonzalez-At JB, Kasner SE, Raps EC. Noninvasive magnetic resonance imaging evaluation of cerebral blood flow with acetazolamide challenge in patients with cerebrovascular stenosis. J Magn Reson Imaging. 1999;10:870-5.

89. Lee JM, Vo KD, An H, Celik A, Lee Y, Hsu CY, Lin W. Magnetic resonance cerebral metabolic rate of oxygen utilization in hyperacute stroke patients. Ann Neurol. 2003;53:227-32.

90. • Lin W, An H, Ford AL, Chen Y, Vo KD, Powers WJ, Lee JM. MR imaging of oxygen extraction and neurovascular coupling. Stroke; a journal of cerebral circulation. 2013;44:S61-64. MROMI in stroke patients.

91. • An H, Ford AL, Chen Y, Vo K, Powers WJ, Lee JM, Lin W. MR oxygenmetabolic index (omi) thresholds for delineating core, penumbra, and oligemia in acute ischemic stroke patients. Int Stroke Conf. 2013:181. This study derived a pair of MROMI thresholds to define core, penumbra and oligemia.

92. • Lee JM, Ford AL, An H, Chen Y, Vo K, Powers WJ, Lin W. Mr-oxygen metabolic index (OMI) is superior to diffusion-perfusion mismatch for predicting tissue fate in the ischemic penumbra. Int Stroke Conf. 2013:12. This study demonstrated that MROMI outperforms DPM in predicting tissue fate in the ischemic penumbra. 